\title{
EVALUATION OF LEVELS OF CLIMATE FAVORABILITY FOR VITICULTURE IN BREASTA VITICULTURAL CENTRE
}

\author{
BUZATU Gilda - Diana \\ assistant professor / Ph.D., Faculty of Agriculture and Horticulture /Department of Biology and Environmental \\ Engineering, University of Craiova, Craiova, Romania, diana_buzatu@yahoo.com \\ MÄR $\breve{A C I N E A N U ~ L i v i u ~ C r i s t i a n ~}$ \\ associate professor / Ph.D., Faculty of Agriculture and Horticulture /Department of Horticulture and Food \\ Science, University of Craiova, Craiova, Romania, maracineanulc@yahoo.com
}

\begin{abstract}
The aim of this present research was to evaluate the climatic conditions of a viticultural centre, as there are always needed studies to determine the climate favorability of the vine cultivation and the varieties resistant to heat and water stress, especially when climate change affects globally viticulture. The present research was made using the interpretation of Craiova Regional Weather Centre's meteorological records for the year of 2014, for Breasta viticultural centre. The climatic factors permitted the determination of several indexes used in viticultural climatology for the appreciation of the viticultural biotope characteristics. Assessment of climatic resources through synthetic climatic indexes, clearly express the generous heliothermic offer available for Breasta viticultural centre, the guarantee of quality and specificity of vine products obtained in this area.
\end{abstract}

Key words: vineyard, climate favorability, climatologic indexes.

\section{Introduction}

Air temperature, solar radiation, rainfall and relative humidity of the air are constantly changing, requiring ongoing studies in order to establish favorability of grapes varieties for table grapes, wine and rootstocks. Genetic factors of climate are meteorological elements that influence the most the development, production and quality of grapes.

The climate assessment of a certain viticultural area does not represent a constant in time, there are permanent variations, depending on the climate origin [1], and therefore, the appreciation of the climatic favourability of a certain region will be much more accurate if synthetic climatologic indexes are used [2]. To characterize the climate of a viticultural area are used climatic indexes that express binary and ternary interaction between ecoclimatic conditions (light, temperature and humidity) [3].

The present research was made using the interpretation of Craiova Regional Weather Centre's meteorological records for the year of 2014, for Breasta viticultural center. The highlighting of climate frame work was made using interpretation of data through the viticulture climatic or specific meteorological indicators as numerical methods for assessing. In this respect, the consulted literature provided a permanent theoretical support in order to characterize the recorded values [4,5,6,7].

\section{Material and method}

The research was based on climatic observations for the viticultural year 2014, as well as on the interpretation of the climatic data recorded for this specific period at the Meteorological Station for Breasta viticultural centre $\left(44^{\circ} 21^{\prime} \mathrm{N}, 23^{\circ} 40^{\prime} \mathrm{E}\right)$. The data used in the analysis of climatic conditions in this area are measured at the Craiova Meteorological Station whose coordinates are: $44^{\circ} 14^{`} \mathrm{~N}$ and $23^{\circ} 52^{`} \mathrm{E}$ and the proximity to the measuring point determine a great significance for the obtained climate data.

In order to analyze the favorability of Breasta viticultural area is necessary to know the main climatic characteristics (light, temperature, and humidity), being important the values that were recorded during the vegetation season, whose conventional boundaries are 1.IV. - 30.IX.2014.

The climatic factors registered permitted the determination of several indexes and coefficients used in viticultural climatology for the appreciation of the viticultural biotope characteristics, such as: active thermal balance, precipitations, real insolation, grapevine bioclimatic index and oenoclimatic 
capacity index. These indexes are representative of the variability of the viticultural climate worldwide, related to the requirements of varieties, vintage quality and typeness of the wines [8].

Climatological Weather Station provided the climatic data and further processing was possible to determine the grapevine synthetic indexes: heliothermic index, Huglin, 1978; hydrothermic index, Seleaninov, 1936; grapevine bioclimatic index, Constantinescu et al., 1964; oenoclimatic capacity index, Teodorescu Şt., 1977.

Breasta viticultural centre is located at intersection of the $23^{\circ} 40^{\prime}$ east meridian with the parallel of $44^{\circ} 21^{\prime}$ north latitude, which places it in the center of Dolj county, being located in the southern Getic plateau, in the hilly Plain of Bălăciţa, located west of Jiu. The relief appears as prolong and broad fields between the bundles valleys tributary to Jiu, which are oriented NW-SE and WE. The NE part of the territory is crossed by Rasnic creek, a tributary of Jiu and in the central part by Breasta creek, a tributary of Rasnic (figure 1). On the larger valleys appear lower alluvial plains and terraces composed of gravel and sand deposits. In general, the relief is hilly plain of lacustrine accumulation, consisting of gravel, sands and thick quilts of clays. Along the valleys appear alluvial and brown soils, favorable to the development of major agricultural crops. Thus, by terracing the slopes the former unproductive pastures have been replaced with large viticultural areas (155 ha) and orchards (64 ha). In addition, within the village still appear forested areas (567 ha), which contribute to the local topoclimate.

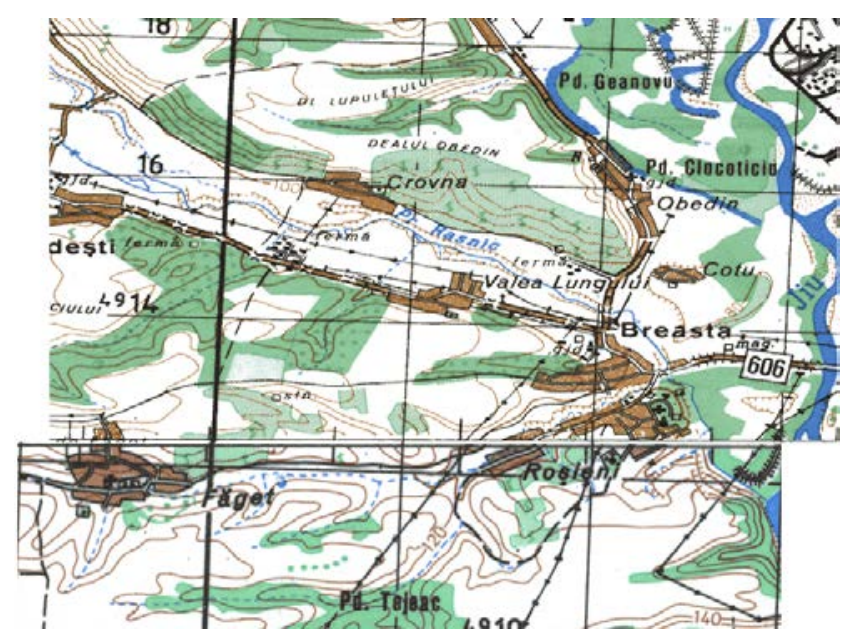

Figure 1: Relief of Breasta, Dolj

Source: Archives of topographic maps at 1: 100,000

From climatic point of view, the region falls in an area with temperate continental climate, characterized by an annual average temperature of approx. $10^{\circ} \mathrm{C}$, absolute maximum temperature of $40^{\circ} \mathrm{C}$ and a minimum temperature of $-30^{\circ} \mathrm{C}$. The first frost occurs after 25 October and the last one in the first decade of April, frost-free period of time being of 200 days/year. The average rainfall is $600 \mathrm{~mm} /$ year.

The dominant winds are from east to west, general atmosphere changes from one season to another being clearly reflected by changes in the frequency of winds in certain directions. Prevailing winds are from the south-west (Cosava - a cold and dry wind, with great destructive power and Austrul a dry wind, accompanied by cold winter and summer stifling heat and drought) and from east, specific winter (Crivatul - cold and dry wind, very violent).

\section{Results and discussions}

As with other crops, the vine is part of an ecosystem created and controlled by man in order to obtain high quality yields, constant from year to year. Unlike from wild plants, which exploit ecological niches which ensure their multiplication, adaptation of vines to environment is facilitated by human intervention.

The factors with the total restrictiveness for vines are excluded along with the choice of place of establishment of the plantation, and those with partial tightness are improved through technological interventions. Adapting to factors whose influence can not be improved (ex. heliothermal regime) depends on the ecological plasticity of each variety. It varies depending on the origin of species and environmental conditions in which the life formed. 
Climatic data are needed for the correct zonation of vine varieties. Each variety requires a certain amount of temperature for its grapes to reach full maturation. Thermal resource requirements vary greatly from one variety to another and are closely related to the length of the growing season of varieties.

Assessment of climate levels of suitability for Breasta vineyard requires knowledge of the main climatic factors (table 1 ).

In the case of vines, the temperature can be analyzed in terms of the factor that determines climate suitability for viticulture. Parameters according to which is assessed the thermal suitability for viticulture are: average annual temperature, thermal balance, the average temperature in July (the hottest month of the year), the level and frequency of minimum temperatures harmful to vines. The vine is grown in areas with mean annual temperature above $9^{\circ} \mathrm{C}$. In areas located at the northern limit of the culture of the vine and at high altitudes, the average annual temperature can be lower, by up to $8.5^{\circ} \mathrm{C}$. In the wine regions with values of mean annual temperature greater than $10^{\circ} \mathrm{C}$ are obtained quality wines.

Temperature coefficient has a value of $15.1^{\circ} \mathrm{C}$. The average temperature of the hottest month (July) provides information about directing the wine centre, thus for the Breasta this temperature is $21.9^{\circ} \mathrm{C}$, indicating that this centre is suitable for growing quality top wines with controlled denomination of origin. The average annual temperature is $18.1^{\circ} \mathrm{C}$, indicating a temperate climate (table 1 ).

The vine is a species with moderate claims against humidity. Daily water consumption of a hub of vines is 0.2 - 1.5 liters of water, which means about 8,000 l/day/ha. During the growing season (April 1 to September 30) water requirement of a plantation with a density of 4,500 vines/ha varies between 2001,920 thousand l/ha, equivalent to a volume amount of rainfall from April till October of $200 \mathrm{~mm}$.

As a part of the precipitation is lost through evaporation and infiltration into the soil, water that remain at the disposal of vines in this volume of rainfall is insufficient, that for optimal supply vines need a volume of 300 - $350 \mathrm{~mm} /$ April - October. For economic culture of the vine, annual rainfall volume should be between 500 and $700 \mathrm{~mm}$. Both excess and deficiency of humidity adversely affect growth of vines, disease resistance and low temperatures, fruit bud differentiation, quantity and quality of production. The amount of rainfall for Breasta viticultural centre is $722.6 \mathrm{~mm}$, also indicating a temperate climate and rainfall coefficient has a value of $3.94 \mathrm{~mm} /$ day (table 1).

Air relative humidity influences the intensity with which the physiological processes are carried out. For vines, optimum air hygroscopicity is $70-80 \%$ during the growth of grains, $60-70 \%$ during the growth of shoots and 55\% during flowering. At $40-50 \%$, photosynthesis slows down and stops at $20 \%$ and vegetative organs die.

Table 1: Climatic characteristics at Breasta viticultural centre in 2014

\begin{tabular}{|c|c|}
\hline Climatic characteristics & 2014 \\
\hline $\begin{array}{l}\text { Average temperature during } \\
\text { the vegetation period, }{ }^{\circ} \mathrm{C}\end{array}$ & 18.1 \\
\hline Average temperature in July & 21.9 \\
\hline Maximum air temperature, ${ }^{\circ} \mathrm{C}$ & 27.8 \\
\hline Minimum air temperature, ${ }^{\circ} \mathrm{C}$ & 5.8 \\
\hline $\begin{array}{l}\Sigma \text { Rainfalls during the } \\
\text { vegetation period, } \mathrm{mm}\end{array}$ & 722.6 \\
\hline Air humidity, \% & 49.38 \\
\hline Real insolation, hours & 1311.7 \\
\hline Global thermal balance, ${ }^{\circ} \mathrm{C}$ & 3325.4 \\
\hline Active thermal balance, ${ }^{\circ} \mathrm{C}$ & 2766.3 \\
\hline Useful thermal balance, ${ }^{\circ} \mathrm{C}$ & 1386.3 \\
\hline
\end{tabular}

The largest amounts of water are taken from the soil surface layers (40 - $60 \mathrm{~cm}$ depth) explored by active roots. Lesser amounts of water, which ensures the survival of hub during periods of drought are taken from deeper soil layers (4 - $6 \mathrm{~m}$ ), reached by few of vine roots.

Solar radiation influences the accumulation of organic compounds in grapes and conditions production and directions of the vineyards. Sunlight deficiency causes poor color of grapes, low-sugar, low aromatic intensity and high level of acidity. Duration of sunshine (actual insolation) during the vegetation period is the sum of the actual sun shine hours between 1.04. - 30.09.2014. In the vineyards of Romania it varies between 1,200 and 1,600 hours, values lower than 1,200 hours being restrictive for vines. 
For Breasta viticultural centre, real insolation has a value of 1311.7 hours and real insolation coefficient has the value of 7.16 hours/day and shows that this viticultural area is indicated for obtaining white wines, flavored wines, sparkling wines and wine distillates (table 1).

Thermal balance varies from year to year, which determines the suitability of different production years for vines. When active thermal balance is higher than the annual average by $3.3 \%$, the year is very favorable for the quality of production, and when the balance is less than $3.7 \%$, the year is unfavorable for quality production.

Regarding the thermal balance, from table 1 are observed the following:

- global thermal balance has a value of $3,325.4^{\circ} \mathrm{C}$ and is within the range of optimal values for viticulture. In the vineyards of Romania it varies between 2,700 and $3,600^{\circ} \mathrm{C}$, values lower than $2,700^{\circ} \mathrm{C}$ are considered restrictive for vines;

- active thermal balance is $2,766.3^{\circ} \mathrm{C}$ and also falls in the optimal values for viticulture; in the vineyards of Romania, it varies between 2,600 and $3,500^{\circ} \mathrm{C}$, values lower than $2,600^{\circ} \mathrm{C}$ being restrictive for vines;

- useful thermal balance, the optimum value for viticulture is in the range of $1,000-1,800^{\circ} \mathrm{C}$, in the case of Breasta viticultural centre, it has the value of $1,386.3^{\circ} \mathrm{C}$, and is also in the optimal range.

Thermal balance is correlated with the anthocyanin content, aromatic compounds, sugars and organic acids. High temperatures hasten the ripening of grapes, favoring the accumulation of anthocyanins, flavors and sugars, while thermal deficit delays the maturation, limiting the accumulation of organic compounds and causes a high level of acidity.

Climatic indexes express the interaction of several elements of climate (temperature, rainfall, relative humidity, real insolation, etc.) and are used for characterizing the potential vineyard at macroclimatic level.

In the global viticulture are used many climatic indexes, most having zonal applicability. For example, grapevine bioclimatic index (index Constantinescu) is used only in areas with temperate climate, because it considers rainfall as unfavorable factor of quality production. To characterize the viticultural areas from Romania, the following climatic indexes are used: heliothermic index, hydrothermic index, grapevine bioclimatic index and oenoclimatic capacity index (table 2).

Huglin heliothermic index reveals availability of thermal and insolation resources of the viticultural areas. It is a variant of Branas heliothermic index obtained by replacing the amount of hours of potential insolation with the amount of actual insolation hours. In the wine regions of Romania, the real heliothermic index varies between 1.35 and 2.7. Values below 1.35 are restrictive for vines. The abundance of thermal resources indicates the possibility of cultivation of varieties for red wine and late maturing table grape varieties. Heliothermic index value in Breasta viticultural centre is 1.81 and indicates that the studied area shows favorability for vine growing and is within the specific limits of vineyards in our country (1.35 to 2.7).

Table 2: The values of the synthetic indexes calculated for Breasta viticultural centre

\begin{tabular}{|c|c|c|c|}
\hline Heliothermic index & Hydrothermic index & $\begin{array}{c}\text { Grapevine bioclimatic } \\
\text { index }\end{array}$ & $\begin{array}{c}\text { Oenoclimatic capacity } \\
\text { index }\end{array}$ \\
\hline 1.81 & 2.61 & 2.77 & 3605.4 \\
\hline
\end{tabular}

Hydrothermic index (Gh. Seleaninov, 1936), expresses the availability of water resources in the viticultural areas of Romania, and varies between 0.6 and 1.8; minimum values are recorded in the south, and maximum levels in Transylvanian Plateau. Values below 0.6 are specific to the arid climate, that requires irrigation of vineyards and highest than 1.8 are specific to cold and wet climate. In the arid areas appear restrictions of crop varieties sensitive to drought, while in areas rich in water resources there is a higher frequency of fungal diseases attacks, especially at compact grapes varieties. Hydrothermic coefficient has a value of 2.61, the viticultural area studied being favorable for obtaining everyday consumption wines.

Grapevine bioclimatic index (Gh. Constantinescu et al., 1964) integrates the influence of temperature, insolation, rainfall and air bioactive period. Its application is limited to areas with temperate climate, where precipitation can be considered an unfavorable factor for the quality of the viticultural production; it does not allow assessing the potential environmental impacts of climate viticultural areas in arid regions, where rainfall is a favorable factor for quality production.

The values recorded in the vineyards of Romania vary between 4.0 and 15.0; optimum ecological balance for vines is recorded when the index has a value of $10 \pm 5$. A low value (4-6) signifies abundance of water resources and high values (12-15) thermal resources abundance and moisture deficit. Values less 
than 4 are restrictive for vines; values greater than 15 are losing their restrictiveness, if there are possibilities for irrigation.

Oenoclimatic capacity index (Teodorescu et al., 1977) expresses the combined action of insolation, temperature and rainfall during the growing season of the vine and reveals possibility of producing red wines in the viticultural area analyzed. In the vineyards of Romania, the index varies between 3,700 and 5,200. The lowest values are recorded in the cold climate conditions from Transylvania, and the highest in southern vineyards rich in heliothermic resources.

According to oenoclimatic capacity index values, at values lower than 4,300 the viticultural area studied is unsuitable for producing red wines (table 2).

Most of the times, it is necessary that the synthetic indicators to be accompanied by the graphic evolution of the climatic factors, namely the climograme. In figure 2 is presented the Bremer climograme for Breasta viticultural centre.

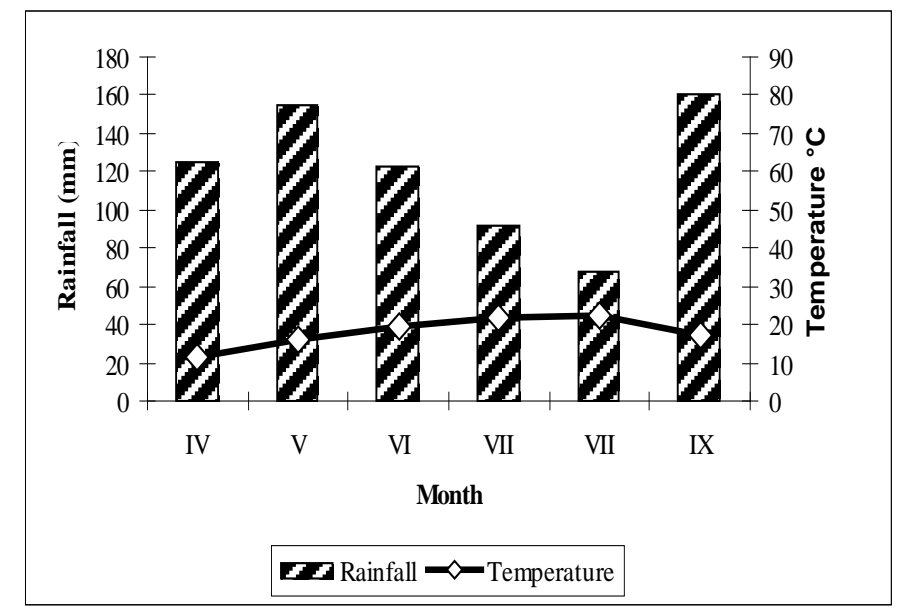

Figure 2: The climograme of Breasta viticultural centre for the year of 2014

According to the climograme of Breasta viticultural centre, the viticultural year 2014 is characterized by rich water resources, the smallest amount of rainfall was recorded in August, $68.2 \mathrm{~mm}$, and the largest amount of $160 \mathrm{~mm}$ was recorded in September, a fact confirmed by the hydrothermic index and at the same time characterized by a progressive increase of the thermal resources up to august, with a value of $22.3^{\circ} \mathrm{C}$ and then to decline in september, having a value of $17.2^{\circ} \mathrm{C}$.

\section{Conclusions}

Manifestation of the climatic factors in Breasta viticultural centre are within optimal limits considered for economic culture of the vines, they exert a favorable influence on growth and fruiting, with implications especially useful on the quantity and quality of crop and on the longevity of plantations in production.

Analysis of data from the viticultural year 2014 revealed atypical values of climatic parameters (high thermal parameters correlated with a high volume of rainfall for the entire period of ripening or near absence of rainfall accompanied by temperature extremes and long duration of sunshine) which had an impact particularly on the dynamic maturation without affecting quality of grape production, on the contrary it has increased, highlighting the value of the viticultural area. The year 2014 was characterized by richness of thermal resources, supplemented by high values of the amount of rainfall, and during the ripening of the grapes has been recorded a severe water deficit.

Climate change threatens to disturb the normal physiological and biochemical processes of the plant with implications for the quality and specificity of vine products. Being a traditional occupation in our country, the Romanian viticulture has established the most favorable areas to obtain quality wines from regions; however, in terms of climate change is now important to monitor the behavior and adaptation of grape varieties to a quality production.

Assessment of climatic resources through synthetic climatic indexes, clearly express the generous heliothermic offer available for Breasta viticultural centre, the guarantee of quality and specificity of vine products obtained in this area.

\section{Acknowledgment}


This work was supported by the strategic grant POSDRU/159/1.5/S/133255, Project ID 133255 (2014), co-financed by the European Social Fund within the Sectorial Operational Program Human Resources Development 2007-2013.

\section{References}

1. Mărăcineanu L.C., Giugea N., Costea D.C, The evolution of the climatic environment specific to the Banu Mărăcine viticultural agroecosystem, Analele Universitătii din Craiova, Vol.X, No.XLVI, pp.27-30, (2005).

2. Mărăcineanu L.C., Giugea N., Olteanu I., Daniela C., Costea D.C., A climatological study of the Banu Mărăcine viticultural centre for an optimal use of the ecological framework through grapevine cultivation, Analele Universitătii din Craiova, Vol.XIII, No.XLIX, pp.83-86, (2008).

3. Mărăcineanu, L.C., Aplicaţii ale ecologiei în viticultură, Universitaria Publishing House, Craiova, România, (2011).

4. Olteanu I., Viticultură, Universitaria Publishing House, Craiova, România, (2000).

5. Oşlobeanu M., Oprean M., Alexandrescu I., Georgescu M., Baniţă P., Jianu L., Viticultură generală şi specială, Didactică şi Pedagogică Publishing House, Bucureşti, România, (1980).

6. Teodorescu Şt., Popa A., Sandu Gh., Oenoclimatul României, Ştiinţifică şi Enciclopedică Publishing House, București, România, (1987).

7. Ariciu, S., Mărăcineanu L.C., Giugea N., Popa C., Costea D., Climatic suitability of some winegrowing centers of Oltenia region for different age of maturation vine crop, Annals of the University of Craiova-Agriculture, Montanology, Cadastre Series, Vol.41, No.1, pp.125-129, (2012).

8. Tonietto J., Carbonneau A., A multicriteria climatic classification system for grape-growing regions worldwide, Agricultural and Forest Meteorology, Vol.124, No.1-2, pp.81-97, (2004). 